\title{
Ferritization of waste printed circuit boards for magnetic separation of common metals
}

\author{
Takanori Hino $^{1 *}$, Youichi Sono ${ }^{2}$ and Ryuichi Agawa ${ }^{2}$ \\ 1 National Institute of Technology, Niihama College, 7-1 Yagumo-cho, Niihama, Ehime 792-8580 Japan \\ 2 First inc., 1-7-30 Ashima, Niihama, Ehime 792-0896 Japan \\ * Corresponding author: Fax: 81-897-37-7802, and/or e-mail: hino@mat.niihama-nct.ac.jp
}

\begin{abstract}
In this research, we examined a method that separates and recovers metals from pulverized powder of printed circuit boards (PCBs) contained in discarded personal computers (PCs). It has been reported that more than $80 \%$ of valuable metals could be recovered after the following processes of crushing, $\mathrm{pH}$ adjustment, and melting. However, as this technique requires an extremely high temperature, it is too costly for practical use at the actual machine level. In particular, a lower cost separation technology is needed for common materials such as $\mathrm{Cu}, \mathrm{Fe}, \mathrm{Ni}$, $\mathrm{Sn}$ and $\mathrm{Pb}$. Instead of the melting process, we apply ferritization process to the PCBs for recovery of common metals by magnetic separation. The PCB slag recovered valuable metals was mixed with several iron oxides powder, and ferritized at a temperature of $1073-1273 \mathrm{~K}$ for 10-60 min under atmosphere. Ferritization of FeO-PCB powder was completed in 10 min at $1073 \mathrm{~K}$. The powder collected on the magnetic side had a saturation magnetization of $7.54 \mathrm{emu} / \mathrm{g}$. The largest amount of ferritized PCBs powder was collected by magnetic separation. And, 95 mass $\%$ of the common metals were recovered.

Key words: Printed circuit boards, Iron oxide powder, Metal recovery, Magnetic separation, Ferritization processing
\end{abstract}

\section{INTRODUCTION}

Until 2014 some 4000 tons of end-of-life PCs were collected annually according to Japan Electronics and Information Technology Industries Association and PC 3R (reduce, reuse and recycle) Promotion Association. In recent years, many institutes have pursued research into recovering precious metals such as gold, silver and platinum from PCBs from PCs, which are discarded in large quantities [1-5]. They have reported the recovery processing for precious metals. Previous researches focusing on common metals recovered in series with precious metals are inadequate. In addition, common metals recovery technology requires many processes such as mechanical, chemical and thermal. Therefore, we have studied the processing for separation and recovery of common metals as well as precious metals by using the dry process that is easy to enlarge for reduction of the processing cost.

We first investigated separation and recovery starting from distillation of PCBs to remove organic components [6]. More than $80 \mathrm{mass} \%$ of the valuable metals present in PCBs can be recovered by first removing the organic components from the PCBs and then subjecting the PCB residue to the following processes: crushing, decarbonization, $\mathrm{pH}$ adjustment, and melting at $1773 \mathrm{~K}$ [7]. However, as these melting techniques involve extremely high temperature processes, which require expensive equipment, it is not feasible for practical applications at the actual machine level [8]. In particular, an inexpensive technique is required for the separation of less valuable materials such as $\mathrm{Cu}, \mathrm{Fe}, \mathrm{Ni}, \mathrm{Sn}$, and $\mathrm{Pb}$ [9]. However, since common metals are present in alloys and also oxidize during processing, it is difficult to separate. These common metals also remained in PCB slag after melting processing.

Kojima et al. have reported that fly ashes containing harmful heavy metals can be magnetized by mixing them with iron oxides and heating to $1073 \mathrm{~K}$ to cause ferritization [10]. It has also been reported that with ferritization, harmful metals contained in waste fluid can be immobilized and magnetically separated [11]. Ferrite is a mixture of ferric oxide and metal oxide, expressed as $\mathrm{MO}-\mathrm{Fe}_{2} \mathrm{O}_{3}$, with a spinel structure. If $\mathrm{M}$ is $\mathrm{Fe}$, the chemical formula is that of $\mathrm{Fe}_{3} \mathrm{O}_{4}$ (magnetite). Metals other than $\mathrm{Fe}$ can be substituted into the crystal lattice of ferrite [12].

Table I Chemical composition of PCB.

\begin{tabular}{ccc}
\hline Material & \multicolumn{2}{c}{$\begin{array}{c}\text { Concentration } \\
\text { (mass \%) }\end{array}$} \\
\hline $\mathrm{C}$ & 6.25 & 6.25 \\
\hline $\mathrm{SiO}_{2}$ & 76.75 & \\
$\mathrm{Al}_{2} \mathrm{O}_{3}$ & 4.44 & 87.76 \\
$\mathrm{CaO}$ & 6.57 & \\
$\mathrm{Cu}$ & 1.29 & \\
$\mathrm{Fe}$ & 0.49 & \\
$\mathrm{Ni}$ & 0.05 & 3.63 \\
$\mathrm{Sn}$ & 1.2 & \\
$\mathrm{~Pb}$ & 0.59 & \\
Noble metals & 0.01 & \\
\hline Others & 2.36 & 2.36 \\
\hline
\end{tabular}


In our metal recovery technique, instead of employing a melting process, we subject PCB slag to the following sequence of steps; distillation heat treatment, crushing, screening, and the removal of free carbon, $\mathrm{pH}$ adjustment, and melting. The PCB slag after these treatments was crushed to a powder, mixed with iron oxide powder, and ferritized at a lower temperature, for the efficient separation and recovery of the common metals.

\section{EXPERIMENTAL}

\subsection{Samples}

Organic materials contained in the PCBs are removed by distillation heat treatment at a temperature of $873 \mathrm{~K}$ in an $\mathrm{Ar}$ atmosphere, then the residual PCBs are crushed in a planetary ball mill to produce particles with sizes of less than $250 \mu \mathrm{m}$ [13]. After distillation, since $40 \mathrm{mass} \%$ of the PCB powder is free carbon, a heat treatment step is added to remove carbon in a gas atmosphere of $95 \% \mathrm{Ar}-5 \% \mathrm{O}_{2}$ [6]. The powder that adjusted basicity was heated at 1773 $\mathrm{K}$ in atmosphere of $97 \% \mathrm{Ar}-3 \% \mathrm{H}_{2}$. The slag and valuable metals were separated. The chemical composition of the PCB slag powder subjected to ferritization is shown in Table I. The iron oxide powders, that are mixed with the PCB slag powder, are $\mathrm{FeO}$ (divalent, Hayashi Pure Chemical Ind., Ltd.), $\mathrm{Fe}_{3} \mathrm{O}_{4}$ (divalent and trivalent, Kojundo Chemical Lab. Co., Ltd), $\mathrm{Fe}_{2} \mathrm{O}_{3}$ (trivalent, Kojundo Chemical Lab. Co., Ltd), or $\mathrm{Fe}(\mathrm{OH})_{3}$ (trivalent, Kanto Chemical Co., Inc.) with particle size of less than $250 \mu \mathrm{m}$. Among these, $\mathrm{FeO}$ and $\mathrm{Fe}_{3} \mathrm{O}_{4}$ are magnetic powder.

\subsection{Ferritization}

For the ferritization step, sample prepared by mixing PCB slag powder $(2 \mathrm{~g})$ with iron oxide powder in various ratios (PCB:iron oxide ratio is denoted as mixture ratio), as shown in Table II, and the resulting mixtures were subjected to atmospheric heat treatment in an electric furnace. Then, the ferritized PCB slag powder was placed in pure water, and wet magnetic separation is performed by stirring with a bar magnet. The ratio of the magnetic material in the powder was determined by dividing the weight of the powder collected on the bar magnet by the total weight of the powder.

\subsection{Analysis of ferritized PCB slag powder}

The constituent phases of ferritized PCB slag powder were identified by comparing $\mathrm{X}$-ray diffraction peaks with

Table II Composition of powders and conditions for magnetic treatment.

\begin{tabular}{cccc}
\hline Condition & PCB : Iron oxide & Temperature (K) & Heating time (min) \\
\hline A & & & 10 \\
B & \multirow{2}{*}{$8: 2$} & 1073 & 30 \\
C & & & 60 \\
\cline { 3 - 4 } D & & 1273 & 10 \\
\hline E & & \multirow{2}{*}{1073} & 10 \\
F & \multirow{2}{*}{$6: 4$} & & 30 \\
G & & 1273 & 60 \\
H & & & 10 \\
\hline I & & 1073 & 10 \\
J & \multirow{2}{*}{$5: 5$} & & 30 \\
K & & & 60 \\
L & & 1273 & 10 \\
\hline
\end{tabular}

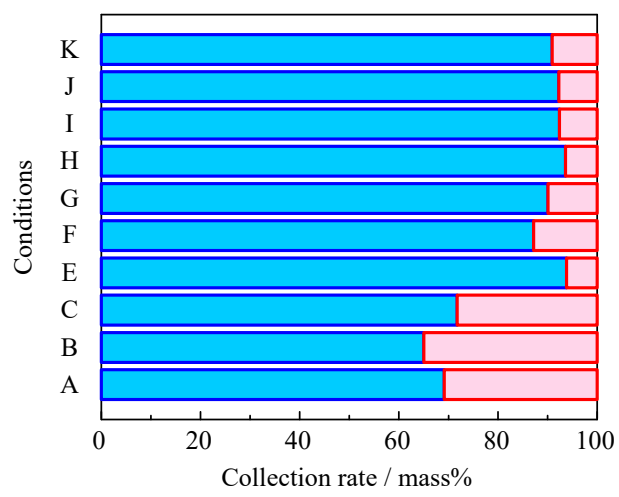

(a) PCB-FeO powder

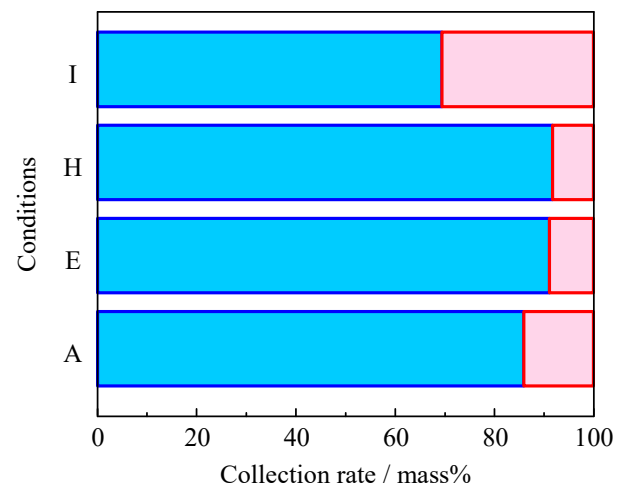

(b) $\mathrm{PCB}-\mathrm{Fe}_{3} \mathrm{O}_{4}$ powder

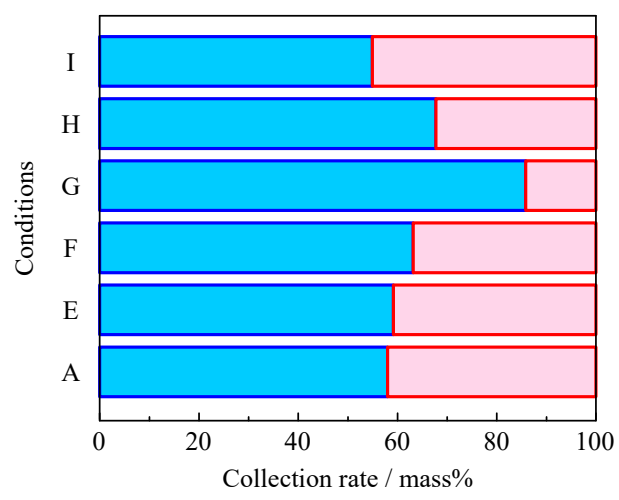

(c) $\mathrm{PCB}-\mathrm{Fe}_{2} \mathrm{O}_{3}$ powder

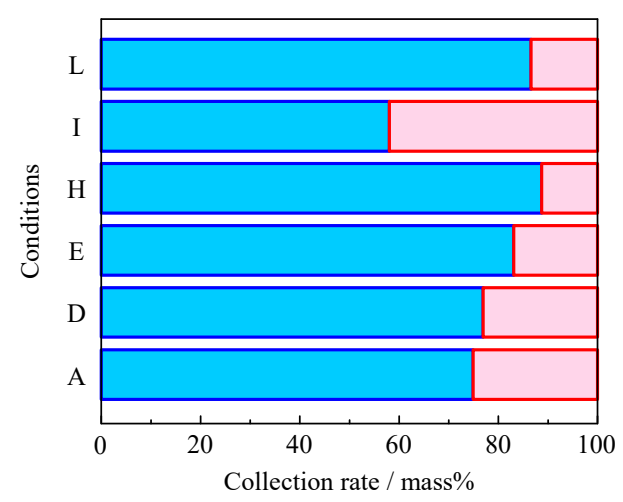

(d) $\mathrm{PCB}-\mathrm{Fe}(\mathrm{OH})_{3}$ powder

Fig. 1 Effects of heating conditions on magnetic filtering. Collection rate on magnetic side: blue bars; collection rate on non-magnetic side: red bars. 
Joint Committee on Powder Diffraction Standards (JCPDS) cards.Scanning electron microscopy (SEM) and energy dispersive $\mathrm{X}$-ray spectroscopy (EDS) were used to observe the appearance and the qualitative composition of the ferritized PCB slag powder obtained after the wet magnetic separation process. The distribution factors of metal ingredients were calculated from the weight of the collected powder and the qualitative analysis results of the EDS. The magnetic properties of the powder were evaluated on the basis of the saturation magnetization and the coercivity values determined from the curve of magnetic flux density (B) versus magnetic field strength (H) plot, as measured with a vibrating sample magnetometer (VSM).

\section{EXPERIMENTAL RESULTS AND DISCUSSION \\ 3.1 Wet magnetic separation from ferritized PCB}

Ferritized at a temperature of $1073 \mathrm{~K}$, the $\mathrm{PCB}$ slag powder was colored gray to dark reddish-brown as the oxidation number of iron oxide mixture changes from divalent to trivalent. In particular, the powder mixture with $\mathrm{Fe}(\mathrm{OH})_{3}$ was a bright brownish red. After ferritization at a temperature of $1273 \mathrm{~K}$, the powder was crushed in a planetary ball mill before being subjected to the wet magnetic separation process. The ferritized PCB easily dispersed in water under stirring.

Fig. 1 shows the ratio of the magnetic material in the slag obtained by ferritic processing. As shown in Fig. 1(a), in the $\mathrm{FeO}-\mathrm{PCB}$ with a mixture ratio of $6: 4$, the magnetic
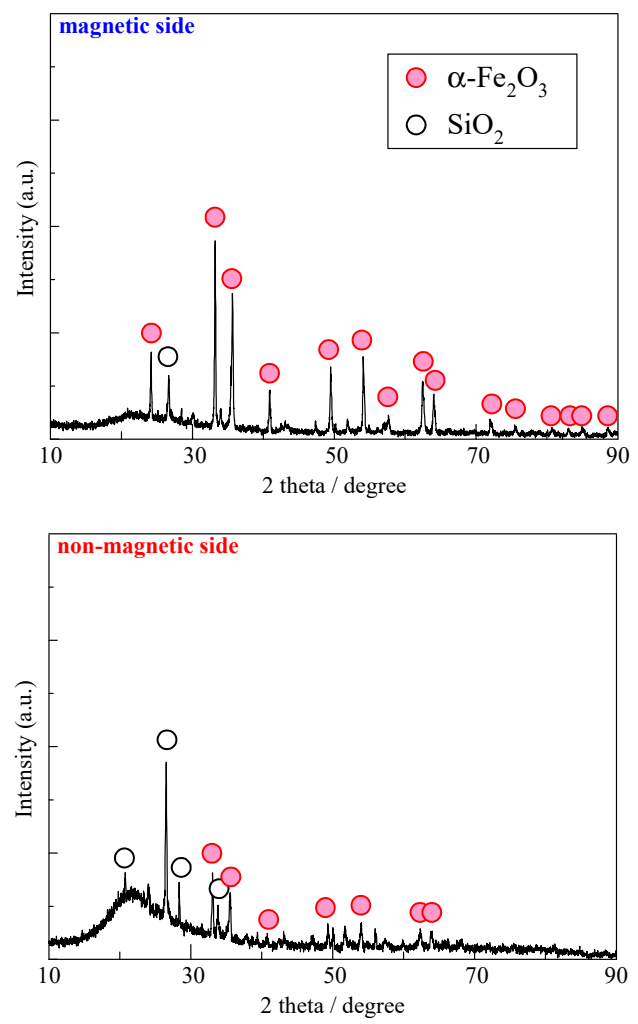

(a) $\mathrm{FeO}-\mathrm{PCB}$ powder material increased with the heat treatment time, and the maximum value of $94 \mathrm{mass} \%$ was obtained at $10 \mathrm{~min}$. A similar tendency was observed for the mixture with a ratio of $5: 5$; the magnetic material content increases to a maximum value of $92 \mathrm{mass} \%$, when heat treatment was carried out for $10 \mathrm{~min}$. In the case of the $\mathrm{FeO}-\mathrm{PCB}$, the magnetic material content of the ferritized PCB powder increases to a maximum upon heat treatment for $10 \mathrm{~min}$, and no further increase was observed even when the treatment time was increased. This indicates that these powders were completely ferritized after treatment for 10 min. Since the maximum amount of the magnetic material in the FeO-PCB powders remains constant at 94 mass $\%$ even after heating to $1273 \mathrm{~K}$, we concluded that heating at temperature above $1073 \mathrm{~K}$ did not yield any additional benefit.

The magnetization time of $10 \mathrm{~min}$, which brought the maximum ratio of magnetic material for $\mathrm{FeO}-\mathrm{PCB}$, was also applied to magnetization using $\mathrm{Fe}_{3} \mathrm{O}_{4}$. As shown in Fig. 1(b), the maximum ratio of magnetic material obtained by the ferritization process was 86 mass $\%$ for the $\mathrm{Fe}_{3} \mathrm{O}_{4}-\mathrm{PCB}$ at a mixture ratio of $6: 4$. If the temperature was increased to $1273 \mathrm{~K}$, the maximum amount of magnetic material decreases to 83 mass $\%$.

In the ferritization using the mixture of $\mathrm{Fe}_{2} \mathrm{O}_{3}$, the magnetic material did not depend on the mixture ratio as shown in Fig. 1(c), but increased with the heat treatment temperature and time. The magnetic material content reached a maximum value of $81 \mathrm{mass} \%$ under the following conditions: mixture ratio of $6: 4$, temperature of
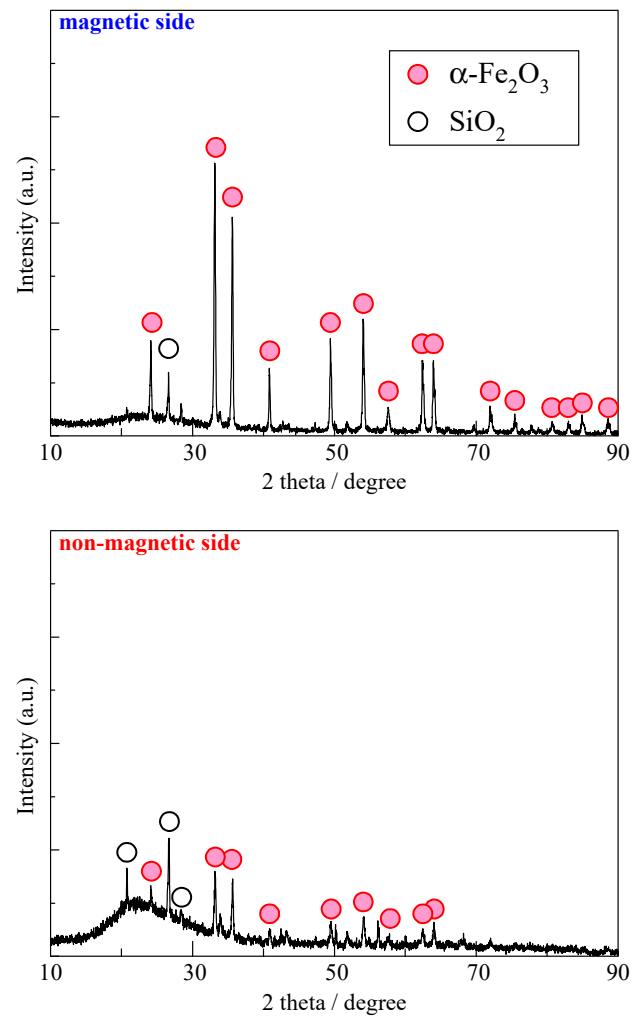

(b) $\mathrm{Fe}_{3} \mathrm{O}_{4}-\mathrm{PCB}$ powder

Fig. 2 X-ray diffraction patterns of ferritized PCB powder collected on magnetic and non-magnetic sides: (a) $\mathrm{FeO}-\mathrm{PCB}$ and (b) $\mathrm{Fe}_{3} \mathrm{O}_{4}-\mathrm{PCB}$. 
$1073 \mathrm{~K}$, and time of $60 \mathrm{~min}$. Furthermore, when the mixture ratio and heat treatment time were fixed at $6: 4$ and $60 \mathrm{~min}$, respectively, the magnetic material content increases from 53 mass $\%$ at $1073 \mathrm{~K}$ to 70 mass $\%$ at $1273 \mathrm{~K}$, indicating that the rate of ferritization increased with temperature.

As shown in Fig. 1(d), in the case of $\mathrm{Fe}(\mathrm{OH})_{3}-\mathrm{PCB}$, the magnetic material content was found to increase with temperature. The maximum value of $86 \mathrm{mass} \%$ was obtained under conditions of a mixture ratio of $6: 4$, a temperature of $1273 \mathrm{~K}$, and time of $10 \mathrm{~min}$.

Compared with before the magnetic separation, after the color became more reddish brown on the magnetic side and grayer on the non-magnetic side. The recovery rate is the greatest at the mixture ratio of $6: 4$. If a small amount of iron oxide is added to the PCB powder, $\mathrm{SiO}_{2}$, which is the major constituent, disturbs the contact between metals and the iron oxide. On the other hand, if excess iron oxide is added, the metals present in the PCB slag powder may react with iron oxide, but the rate of formation of magnetic substances remain relatively small because metals to be separated are not efficiently supplied. The formation of magnetic substances decreased as the oxidation number of the added iron oxide changes from divalent to trivalent. If $\mathrm{FeO}$ (divalent) or $\mathrm{Fe}_{3} \mathrm{O}_{4}$ (mixture of divalent and trivalent) are added, complete ferritization occurs in a short period of time even at lower temperatures. These experimental results suggest that a higher temperature and a longer time are required for magnetization when using stable trivalent oxides that are $\mathrm{Fe}_{2} \mathrm{O}_{3}$ or $\mathrm{Fe}(\mathrm{OH})_{3}$. For the formation of magnetic substances, the optimal result was obtained from the $\mathrm{FeO}-\mathrm{PCB}$ mixture.

\subsection{Characterization of ferritized PCB}

Fig. 2 shows the $\mathrm{X}$-ray diffraction of ferritized $\mathrm{PCB}$ slag powder, where the major peaks indicate hematite $\left(\alpha-\mathrm{Fe}_{2} \mathrm{O}_{3}\right)$, which is hexagonal and non-magnetic, although the diffraction peak intensity depends on the type of added iron oxide. Peaks from the magnetics, namely, magnetite $\left(\mathrm{Fe}_{3} \mathrm{O}_{4}\right)$ and mag-hematite $\left(\gamma-\mathrm{Fe}_{2} \mathrm{O}_{3}\right)$, were not found. As the oxidation number of the mixed iron oxide changed from divalent to trivalent, the hematite peaks become larger. In the gray powder in the non-magnetic side after the ferritization of PCB powder, a broad

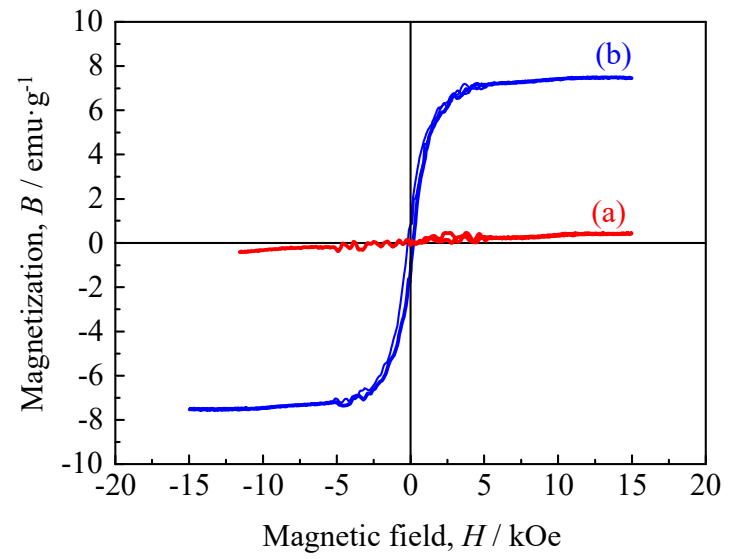

Fig. 3 Magnetization as a function of magnetic field for (a) $\mathrm{Fe}_{2} \mathrm{O}_{3}$ powder and (b) ferritized $\mathrm{FeO}-\mathrm{PCB}$ powder, measured with a VSM at $290 \mathrm{~K}$. diffraction pattern at lower angle and diffraction peaks from $\mathrm{SiO}_{2}$ were found, suggesting that the material is glass fiber.

The fact that the PCB powder collected on the magnetic side was composed of hematite $\left(\alpha-\mathrm{Fe}_{2} \mathrm{O}_{3}\right)$, which was non-magnetic, may seem to contradict the notion of magnetic separation. Fig. 3 shows the evaluated magnetic characteristics of $\mathrm{FeO}-\mathrm{PCB}$ collected on the magnetic side. The saturation magnetization of the $\alpha-\mathrm{Fe}_{2} \mathrm{O}_{3}$ powder used for mixture, was as low $0.61 \mathrm{emu} / \mathrm{g}$, showing that the material is essentially non-magnetic. On the other hand, the $\mathrm{FeO}-\mathrm{PCB}$ powder collected by magnetic separation on the magnetic side had a saturation magnetization of 7.54 emu/g. These indicate that the collected materials on the magnetic side after ferritization using $\mathrm{FeO}$ have magnetic,
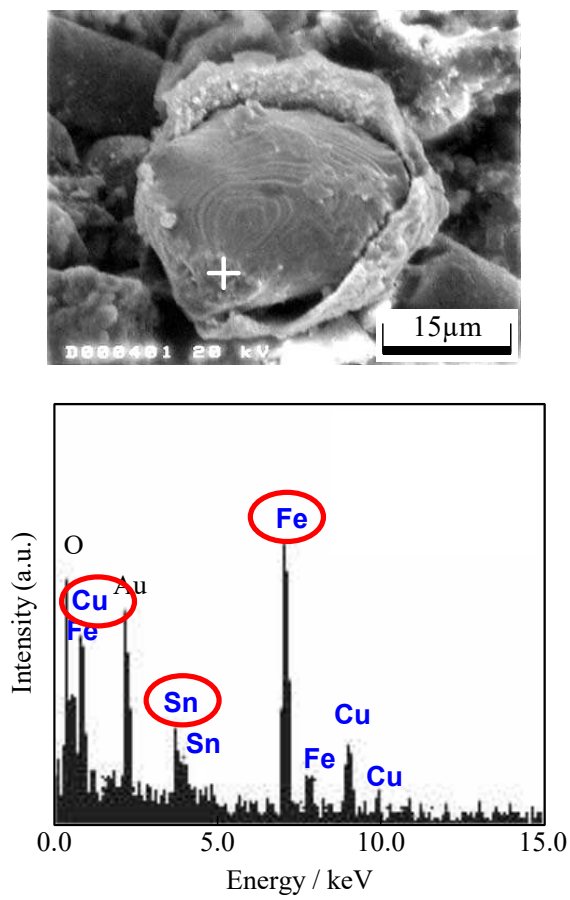

Fig. 4. SEM image and EDX spot analysis of FeO-PCB powder after magnetization treatment.

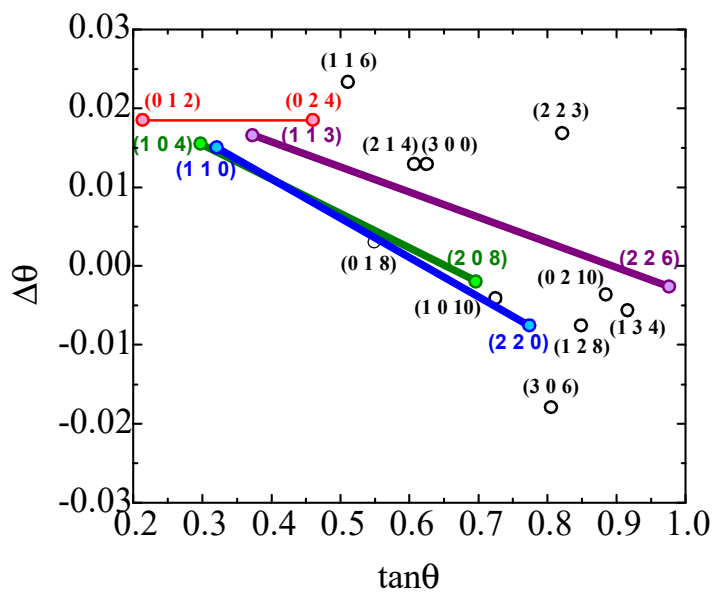

Fig. 5 Plots of $\Delta \theta$ as a function of $\tan \theta$ for ferritized $\mathrm{FeO}-\mathrm{PCB}$ powder. 


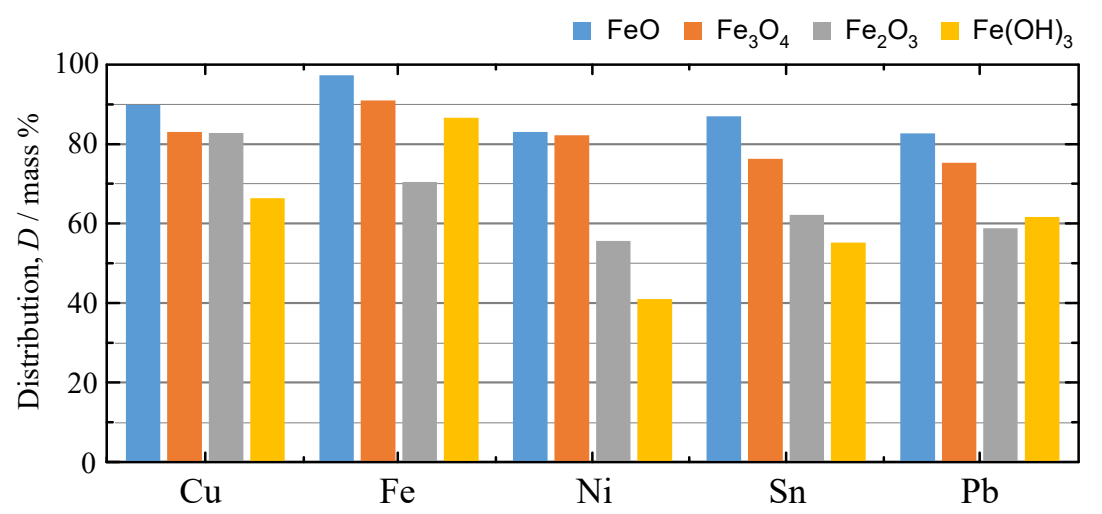

Fig. 6 Average distribution factor of metal in ferritized PCB powder collected on magnetic side.

although the residual magnetization of $1.01 \mathrm{emu} / \mathrm{g}$ and coercivity of $0.19 \mathrm{kOe}$ were low. This is most probably because of the magnetization of the PCB powder during the ferritization process.

Fig. 4 shows an SEM image and the result of EDS analysis for the $\mathrm{FeO}-\mathrm{PCB}$ on the magnetic side. The EDS spectrum of Au was observed simply because gold was evaporated for SEM observation. The spectrums of $\mathrm{Cu}$ and $\mathrm{Sn}$ were detected in addition to $\mathrm{Fe}$ in the powder after ferritization. The fact that the diffraction peaks of these metals were not observed in XRD suggests that the metals were dissolved in the main component of $\alpha-\mathrm{Fe}_{2} \mathrm{O}_{3}$ in the reddish brown powder collected on the magnetic side.

To consider ferritization using $\alpha-\mathrm{Fe}_{2} \mathrm{O}_{3}$, we next examined the change in lattice spacing due to the formation of a substitutional solid solution of metal atoms such as $\mathrm{Cu}(1.28 \AA)$ and $\mathrm{Sn}(1.41 \AA)$, of which the atomic radii are greater than that of $\mathrm{Fe}(1.24 \AA)$. By totally differentiating Bragg's law and rearranging, the following equation is derived:

$$
\Delta \theta=-\frac{\Delta d}{d} \tan \theta
$$

The change in lattice spacing can be evaluated from the relation between the peak position difference of $\Delta \theta$ in Eq. (1) and the diffraction angle of $\tan \theta$. Commercial $\alpha-\mathrm{Fe}_{2} \mathrm{O}_{3}$ powder was used as a standard for the value of $d$. The value of $\Delta \theta$ and $\Delta \mathrm{d}$ are derived from the XRD data of $\alpha-\mathrm{Fe}_{2} \mathrm{O}_{3}$ obtained in this study after ferritization. Figure 5 shows the relation between $\Delta \theta$ and $\tan \theta$. $\Delta \theta$ is identical for the $\left(\begin{array}{lll}0 & 1 & 2\end{array}\right)$ and $\left(\begin{array}{lll}0 & 2 & 4\end{array}\right)$ planes, which are unrelated to the a-axis, and no change was detected in the lattice spacing. On the other hand, comparing the (llll 113$)$ and $\left(\begin{array}{lll}2 & 2 & 6\end{array}\right),\left(\begin{array}{ll}1 & 0\end{array}\right.$ 4) and ( $\left.\begin{array}{lll}2 & 0 & 8\end{array}\right),\left(\begin{array}{lll}1 & 1 & 0\end{array}\right)$ and $\left(\begin{array}{lll}2 & 2 & 0\end{array}\right)$ planes, $\Delta \theta$ decreases with increasing of diffraction angle. The inclination $(-\Delta \mathrm{d} / \mathrm{d})$ was negative for the straight line connecting the each $\Delta \theta$ values of the planes involving the a-axis. These straight lines for $\{113\},\{104\}$, and $\{110\}$ were -0.04977 , -0.04405 , and -0.03154 , respectively. The inclination also became bigger so that spacing of lattice plane was smaller. Assuming that the c-axis length is equal to that of the $\alpha-\mathrm{Fe}_{2} \mathrm{O}_{3}$ used in the mixture, the extracted a-axis length of $\alpha-\mathrm{Fe}_{2} \mathrm{O}_{3}$ is $5.197 \AA$. In other words, the a-axis is $2.78 \%$ longer than that of standard $\alpha-\mathrm{Fe}_{2} \mathrm{O}_{3}$. This is very possibly related to the fact that $\mathrm{PCB}$ powder was magnetized by the ferritization process. It is expected that metals such as $\mathrm{Cu}$, $\mathrm{Ni}$, and $\mathrm{Sn}$ in the PCB powder react with iron oxide during the ferritization process. Due to the presence of dissolved metals, the lattice spacing in $\alpha-\mathrm{Fe}_{2} \mathrm{O}_{3}$ changes, and magnetization occurs when lattice distortion and disorder are brought about in the anti-ferromagnetic structure. [12]

\subsection{Metal recovery rates}

Fig. 6 shows the distribution factors of $\mathrm{Cu}, \mathrm{Fe}, \mathrm{Ni}, \mathrm{Sn}$, and $\mathrm{Pb}$ on the magnetic side after ferritization of the $\mathrm{PCB}$ slag using the condition optimized for the ratio of magnetic material: mixture ratio of $6: 4$, temperature of $1073 \mathrm{~K}$, and processing time of $10 \mathrm{~min}$.

The distribution factor of $\mathrm{Cu}$ was $96 \mathrm{mass} \%$ using the $\mathrm{FeO}-\mathrm{PCB}$ mixture. The distribution factor of $\mathrm{Fe}$ was always greater than 90 mass $\%$ using the powder containing $\mathrm{FeO}$ and $\mathrm{Fe}_{3} \mathrm{O}_{4}$. In particular, $\mathrm{FeO}-\mathrm{PCB}$ showed a distribution factor greater than 97 mass $\%$, which proved to be optimal for the collection of Fe. The distribution factor of $\mathrm{Ni}$ was 96 mass\% with $\mathrm{FeO}, 94 \mathrm{mass} \%$ with $\mathrm{Fe}_{3} \mathrm{O}_{4}$, 86 mass\% with $\mathrm{Fe}_{2} \mathrm{O}_{3}$, and 89 mass $\%$ with $\mathrm{Fe}(\mathrm{OH})_{3}$. The distribution factor of $\mathrm{Ni}$ was similar to that of $\mathrm{Fe}$. It is suggested that the distribution factor of $\mathrm{Fe}$ influences that of $\mathrm{Ni}$ because $\mathrm{Ni}$ exists mostly in the form $\mathrm{Fe}-\mathrm{Ni}$. The distribution factor of $\mathrm{Sn}$ was greater than $90 \mathrm{mass} \%$ with $\mathrm{FeO}, \mathrm{Fe}_{3} \mathrm{O}_{4}$, or $\mathrm{Fe}(\mathrm{OH})_{3}$. Since $\mathrm{Sn}$ usually exists in the form of $\mathrm{Cu}-\mathrm{Sn}$ in $\mathrm{PCB}$ powders, $\mathrm{Sn}$ moves to the magnetic side as the ferritization of $\mathrm{Cu}$ proceeds. The distribution factor of $\mathrm{Pb}$ was high only in the $\mathrm{FeO}-\mathrm{PCB}$ mixture.

On the magnetic side, the distribution factor was greater than 90 mass $\%$ for all metal components for the $\mathrm{FeO}-\mathrm{PCB}$ or $\mathrm{Fe}_{3} \mathrm{O}_{4}-\mathrm{PCB}$ powder mixture. The distribution factors of all metals on the magnetic side decreased as the oxidation number of the iron oxide mixture closes the trivalent state. Ferritization is a technique of mixing $\mathrm{Fe}_{2} \mathrm{O}_{3}$ for the recovery of valuable metals by magnetic separation. However, dry ferritization is extremely costly because $\mathrm{Fe}_{2} \mathrm{O}_{3}$ must be heated to over $1673 \mathrm{~K}$ for generation of magnetite. Note that the trivalent $\mathrm{Fe}(\mathrm{OH})_{3}$ is the most stable iron hydroxide. This is the reason why we could collect only a small amount of magnetic materials by using $\mathrm{Fe}(\mathrm{OH})_{3}$, being next only to $\mathrm{Fe}_{2} \mathrm{O}_{3}$. Divalent $\mathrm{Fe}$ is easily oxidized and forms highly stable trivalent oxides. $\mathrm{FeO}$ is crystallographically unstable and is therefore very reactive. When it is oxidized, it enhances solid-state dissolution and oxidation of metallic elements in the PCB slag powder. The resulting solid-state solution would causes disorder in the crystal structures of $\alpha-\mathrm{Fe}_{2} \mathrm{O}_{3}$, and 
therefore the $\mathrm{FeO}-\mathrm{PCB}$ powder was more strongly magnetized. The ferritization causes strong aggregation of the metal composition on the magnetic side in a ratio exceeding 90 mass $\%$, thus making magnetic separation highly efficient.

In this study, since the processing temperature is as low as $1073 \mathrm{~K}$ and the added iron oxide is also inexpensive, it can be expected the continuous processing at large amount in a short time using a rotary kiln at lower cost than the conventional recycle processing. Furthermore, we suggest that the hematite powder prepared in this study can be reused as abrasives, colored pigments, building materials and magnetic materials.

\section{SUMMARY}

This study focused on the ferritization of pulverized PCBs present in discarded PCs for recovery of common metals. Different PCB-iron oxide mixture were subjected to ferritization for magnetic separation, and the metal recovery rate in each case was determined. Ferritization of FeO-PCB mixture was completed in $10 \mathrm{~min}$ at $1073 \mathrm{~K}$. Maximum efficiency was achieved with a mixture ratio of $6: 4$ irrespective of the iron oxide used. The largest amount of powder was collected on the magnetic side, although ferritized PCB slag was composed of non-magnetic $\alpha-\mathrm{Fe}_{2} \mathrm{O}_{3}$ as shown in $\mathrm{X}$-ray diffraction. Furthermore the lattice parameter of the ferritized $\alpha-\mathrm{Fe}_{2} \mathrm{O}_{3}$ was extracted to a-axis direction. This powder had a saturation magnetization of $7.54 \mathrm{emu} / \mathrm{g}$. We suggested that magnetization of the PCB slag have been caused during the ferritization process. On the magnetic side, the distribution factor was greater than $90 \mathrm{mass} \%$ for all common metal components such as $\mathrm{Cu}, \mathrm{Fe}, \mathrm{Ni}, \mathrm{Sn}$, and $\mathrm{Pb}$. We suggested that the ferritization would causes lattice distortion and disorder in the crystal structures of $\alpha-\mathrm{Fe}_{2} \mathrm{O}_{3}$. The magnetic separation became highly efficient because FeO-PCB became more strongly magnetized by ferritization treatment.

\section{REFERENCES}

[1] J. Cui and E. Forssberg, Journal of Hazardous Materials, B99, 243-263 (2003)

[2] H. Y. Kang and J. M. Schoenung, Resources, Conservation and Recycling, 45, 368-400 (2005)

[3] C. Leea, C. Changb, K. Fanc, and T. Chang, Journal of Hazardous Materials, B114, 93-100 (2004)

[4] R. Hischier, P. Wäger, and J. Gauglhofer, Environmental Impact Assessment Review, 25, 525-539 (2005)

[5] C. Hagelüken, World of Metallurgy ERZMETALL, 59, 152-161 (2006)

[6] T Hino, Y Moriya, R Agawa, Y Tsugita, M Nishida and T Araki, Journal of Environment and Engineering, $\mathbf{5}$, 383-388 (2010)

[7] T. Hino, R. Agawa, Y. Moriya, M. Nishida, Y. Tsugita, and T. Araki, J. Mater. Cycles and Waste Manag., I, 42-54 (2009)

[8] Johan Sohaili, Shantha Kumari Muniyandi and Siti Suhaila Mohamad, Journal of Emerging Trends in Engineering and Applied Sciences, 3, 12-18 (2012)

[9] A. Arensen Aier D. Prabhakaran T. Kannadasan, International Journal of Scientific Research, 2, 209-212
(2013)

[10] Kojima and T. Yanagisawa, Journal of resource and environment, 30, 25-31 (1994)

[11] J. Kimura and S. Ohno, NEC Technical Journal, 37, 43-47 (1984)

[12] E. Gorter, Philips Res. Rep., 9, 295-320 (1954)

[13] T. Hino, D. Narahara, R. Agawa, Y. Tsugita, M. Nishida, and T. Araki, J. Mater. Cycles and Waste Manag., 5, 137-142 (2003)

(Received February 26, 2018; Accepted April 16, 2018; Published Online June 1, 2018) 